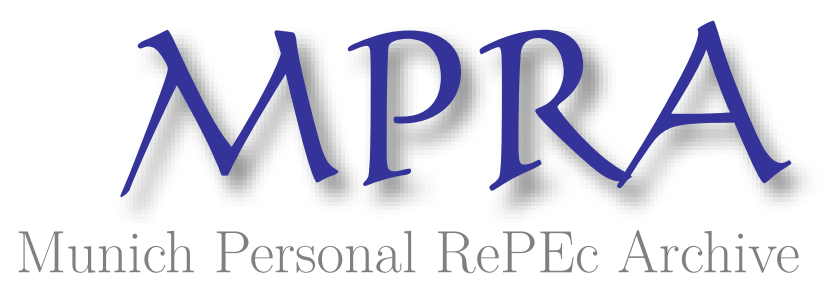

\title{
Learning-by-Doing and Cannibalization Effects at Multi-Vintage Firms: Evidence from the Semiconductor Industry
}

Siebert, Ralph Bernd

Purdue University

12 March 2010

Online at https://mpra.ub.uni-muenchen.de/24008/

MPRA Paper No. 24008, posted 21 Jul 2010 06:13 UTC 
An Article Submitted to

The B.E. Journal of Economic

Analysis \& Policy

Manuscript 1946

Learning-by-Doing and

Cannibalization Effects at

Multi-Vintage Firms: Evidence from

the Semiconductor Industry

\author{
Ralph B. Siebert*
}

*rsiebert@purdue.edu

Copyright (c) 2010 The Berkeley Electronic Press. All rights reserved. 


\title{
Learning-by-Doing and Cannibalization Effects at Multi-Vintage Firms: Evidence from the Semiconductor Industry
}

\author{
Ralph B. Siebert
}

\begin{abstract}
Previous studies on the measurement of learning-by-doing emphasize the importance of accounting for multi-vintage effects having an impact on firms' production costs through economies of scope. This study shows that accounting for cannibalization effects on the demand side is equally important for the adequate measurement of learning. Since multi-vintage firms anticipate the demand-side cannibalization effects in their production optimization, a previously omitted incentive to decrease production is captured having an impact on the measurement of learning by doing. We derive an empirical model from a dynamic oligopoly game of learning-by-doing and allow cannibalization effects to enter from the demand side. Using quarterly firm-level data for the dynamic random access memory semiconductor industry, we find support for cannibalization effects entering firms' pricing relations resulting in higher estimated learning effects.
\end{abstract}

KEYWORDS: Dynamic Random Access Memory, Dynamics, Economies of Scale, Learning by Doing, Multiproduct Firms, Product Life Cycle, Semiconductors 


\title{
Learning-by-Doing and Cannibalization Effects at Multi-Vintage Firms: Evidence from the Semiconductor Industry
}

\author{
September 2009
}

\begin{abstract}
Previous studies on the measurement of learning-by-doing emphasize the importance of accounting for multi-vintage effects having an impact on firms' production costs through economies of scope. This study shows that accounting for cannibalization effects on the demand side is equally important for the adequate measurement of learning. Since multi-vintage firms anticipate the demand-side cannibalization effects in their production optimization, a previously omitted incentive to decrease production is captured having an impact on the measurement of learning by doing. We derive an empirical model from a dynamic oligopoly game of learning-by-doing and allow cannibalization effects to enter from the demand side. Using quarterly firm-level data for the dynamic random access memory semiconductor industry, we find support for cannibalization effects entering firms' pricing relations resulting in higher estimated learning effects.
\end{abstract}

JEL: C1, L1, L6, O3.

Keywords: Dynamic Random Access Memory, Dynamics, Economies of Scale, Learning-by-Doing, Multi-Vintage Firms, Semiconductors.

Acknowledgments: I would like to thank the "Journal of Industrial Economics" for awarding this study with the "Young Economists' Prize." I would also like to thank Ernst R. Berndt, Paul Geroski, Gautam Gowrisankaran, Bronwyn Hall, Paul Hanouna, Marc Ivaldi, Dale Jorgenson, Fiona Scott Morton, Ariel Pakes, Martin Pesendorfer, Lars-Hendrik Röller, Margaret Slade, Minjae Song, Otto Toivanen, Frank Verboven, Christine Zulehner, participants of the Industrial Organization workshop at Harvard University and an anonymous referee for helpful comments and suggestions. I am grateful to Harvard University, the NBER and the "VolkswagenStiftung" for hospitality and financial support. All remaining errors are my own. 


\section{Introduction}

An important aspect to consider in designing subsidy programs and promoting entry and industry growth is learning-by-doing . ${ }^{1}$ Learning-by-doing may have crucial consequences on market structure and is important for firms to consider when determining their optimal production rates. It improves operations either through reduced time, lower labor costs, or reduced material waste (see e.g., Dick, 1991; Fudenberg and Tirole, 1983; Lieberman, 1982 and 1984; Majd and Pindyck, 1989; Spence, 1981; and Wright, 1936).

This study stresses the importance of controling for cannibalization effects on the demand side when estimating learning-by-doing effects. We are not aware of any empirical study that focuses on the relationship between learning-by-doing and cannibalization. With respect to learning-by-doing and cannibalization, output decisions by multi-vintage firms are characterized by the following two opposing effects: (i) raising a vintage's output achieves higher cost reductions in the future through learning, which induces firms to increase their output, and (ii) raising a vintage's output further cannibalizes the demand of other vintages (in case they are imperfect substitutes). ${ }^{2}$ Hence, firms anticipate the cannibalization effects in their production optimization. The inclusion of the second effect (ii) attributes a higher production rate to the achievement of future cost reductions through learning which results in higher estimated learning-by-doing effects.

Workers and managers learn from their past experiences and improve their operations such that firms become more efficient. Firms account for the fact that drastically expanding output at the early stage of the life cycle has the advantage

\footnotetext{
${ }^{1}$ Miravete (2003) investigates whether a government is able to protect a domestic monopoly against foreign competition which faces learning-by-doing effects. Export subsidies provided to the Japanese steel industry in the 1950's and 1960's, caused remarkable growth in production (more than $400 \%$ from 1953 to 1964, and exports increased by $20 \%$ per year), raising Japan to the largest steel exporter.

${ }^{2}$ Cannibalization effects on the demand also enter firms' production plans as firms' contemporaneous output decision of one vintage determines future prices and demand of other vintages through substitution effects.
} 
of moving down the cost curve quickly. The effect of moving down the learning curve quickly becomes even more important when production is interpreted as a commitment device. A firm can exploit an advantage in greater production speed or in a headstart of introducing a new vintage by moving down the learning curve quickly and achieving a Stackelberg leader position instead of Nash, see Fudenberg and Tirole (1986 and 1991). The leader tries to enforce its Stackelberg outcome by accumulating enough production before the follower reaches its reaction curve.

Stokey (1988) stresses that learning-by-doing also contributes to growth if experience of one vintage reduces costs for consecutive vintages. Recent empirical studies account for learning across vintages or dynamic economies of scope, see e.g., Cohen and Levinthal (1989 and 1990), Irwin and Klenow (1994), Benkard (2000) and Thornton and Thompson (2001). Gruber (1992) considers learning effects in a sequence of product innovations. He shows that learning effects may result in a persistence of leadership with firms having stable market shares over a sequence of different vintages. For further information about how learning within and across vintages affect market structure and performance, see also Ghemawat (1985) and Ghemawat and Spence (1985).

Similar to the relationships between vintages on the supply side through learning, vintages might also be related on the demand side through substitution effects. If products or vintages are (imperfect) substitutes, an increase in quantity of one vintage will cannibalize the demand for other vintages. Hence, cannibalization occurs when interrelations exist between vintages on the demand side, caused by substitution effects (see also Anderson, de Palma, and Thisse, 1992). ${ }^{3}$ Cannibalization has frequently been investigated in the literature. Prominent contributions are Moorthy and Png (1992), Mussa and Rosen (1978), Norton and Bass (1987) and Urban, Johnson and Hauser (1984). Firms producing multiple vintages make their output decisions at a centralized level such that they control for substitution and cannibalization effects within their own product line (see e.g., Berry, 1994; Berry, Levinsohn

\footnotetext{
${ }^{3}$ Product cannibalization has been defined as "the process by which a new product gains a portion of its sales by diverting them from an existing product," see Heskett (1976).
} 
and Pakes, 1995; Bresnahan, 1987; Goldberg, 1995; and Verboven, 1996). Aizcorbe and Kortum (2005) and Song (2007) investigate the relationship between the introduction of new vintages, cannibalization effects and drastically declining prices in the microprocessor market.

The difficulty in measuring learning effects is that cost data are often not available. Most studies, therefore, attribute firms' production incentives to the measurement of learning effects. For an adequate measurement of learning it is required to encompass firms' production incentives. Production incentives might be influenced by interlinkages between products on the supply side (e.g., learning across vintages), or by interlinkages between products on the demand side (e.g., cannibalization caused by substitution effects).

We specify a dynamic oligopolistic state-space game and estimate a dynamic model consisting of demand and pricing equations. Using quarterly firm-level data for the dynamic random access memory semiconductor industry, we find strong support that cannibalization on the demand side has an impact on the measurement of learning-by-doing rates. We provide evidence that accounting for a multi-vintage firm specification results in learning-by-doing estimates of around 20\%, which are around $10 \%$ higher than in our benchmark case, which builds on a single-vintage firm specification.

The remainder of this study is organized as follows. Section 2 discusses the characteristics of the semiconductor industry and introduces the data. In Section 3 , we present the theoretical model of learning-by-doing with multi-vintage firms. Section 4 describes the empirical model. We present the results in Section 5 and conclude in Section 6.

\section{The Semiconductor Industry}

Several empirical studies focus especially on the innovation and learning aspects in the semiconductor industry. For example, Hatch and Mowery (1998) examine the relationship between process innovation and learning-by-doing. Hall and Ziedonis 
(2001) emphasize that the semiconductor industry is characterized by rapid technological change and cumulative innovation. ${ }^{4}$ Gruber (1992) also notes that learning enters the manufacturing process through the fine-tuning of production processes. For related work in this industry, see also Aizcorbe and Kortum (2005), Irwin and Klenow (1994), Flamm (1993a and 1996), Gruber (1998), and Nye (1996), Song (2007) and Zulehner (2003).

In capital-intensive industries, such as the semiconductor industry, learning mostly occurs through improving manufacturing technologies and reducing material waste. ${ }^{5}$ The reduction of the required amount of silicon increases the yield rate which reduces firms' costs. ${ }^{6}$ When firms engage in learning-by-doing their unit cost decline over time, for production experience is accumulated through past output. Figure 1 illustrates that learning also brings an intertemporal dimension to a firm's output strategy, as current output yields cost savings in the future. Firms' optimal strategy is to further increase production, in order to invest in future cost reductions. Hence, they set their output according to their dynamic marginal costs $\left(M C^{D}\right)$ which lie below their static marginal costs $\left(M C^{s}\right) .{ }^{7}$ Firms may even obtain negative mark-ups by pricing according to their dynamic marginal costs. The enormous decline of different vintage prices (see Figure 2) is often explained as a consequence of quantities being set according to shadow marginal costs.

Another aspect of learning-by-doing is the "organizational forgetting" hypothesis. There is a large body of literature focusing on organizational forgetting, the fact

\footnotetext{
${ }^{4}$ Jorgenson (2001) points out that the semiconductor market is an important industry, as the enormous price decline has been transmitted to product prices that rely heavily on the semiconductor market, i.e., the aircraft, automobiles, and scientific instruments industries. Jorgenson and $\mathrm{Vu}$ (2005) emphasize the impact of investment in information technology on the world economic growth.

${ }^{5}$ In contrast, for labor-intensive industries, such as the aircraft and shipbuilding industries, learning is rather characterized by improving workers' and managers' operations, see e.g., Benkard (2000), and Thornton and Thompson (2001).

${ }^{6}$ The yield rate measures the ratio of chips that pass the quality test, divided by the total number of chips.

${ }^{7}$ Figure 1 is taken from Dick (1991).
} 
that experience may depreciate over time. Heiman, McWilliams, Shen, and Zilberman (2001), and Argote, Beckman, and Epple (1990) show that not accounting for forgetting may overstate the persistence of learning-by-doing. Benkard (2000) shows that in the aircraft industry, firms' production experience depreciates heavily over time. We do not explicitly account for organizational forgetting in our model, as we are interested in highlighting the mismeasurement of learning due to neglecting demand-side cannibalization effects. Moreover, organizational forgetting is a crucial aspect in labor-intensive industries, but not as important in capital-intensive industries, like the semiconductor industry. Note that the learning rate in our analysis represents a net learning rate, gross learning less forgetting.

In the following, we introduce the Dynamic Random Access Memory (DRAM) industry and highlight the extent to which this industry is characterized by multivintage firms: DRAM vintages or chips are one type of semiconductor and is mainly used for the storage of information in binary form and deployed as inputs for the computer industry, consumer electronics, and communications equipment. The DRAM market is characterized by firms from the United States, Japan, Korea and Europe, with a $18.1 \%, 48.5 \%, 2.1 \%$, and $31.3 \%$ market share, respectively, in 1996 (Dataquest). DRAM chips differ in their capacity to store binary information units. For example, the $4 \mathrm{~K}$ DRAM chip is capable of storing $4 \mathrm{~K}$ binary information units. The memory capacity of successive vintages typically increases by a factor of four. DRAM vintages represent homogenous goods in themselves, but represent (vertically) differentiated goods across vintages (see Flamm, 1996; Gruber, 1996; and Irwin and Klenow, 1994). ${ }^{8}$

The sales of chips are very much characterized by a product life cycle: once a vintage is launched, shipments increase enormously and begin to fall when a successive vintage is introduced. The life cycles last for about five years and look very similar to each other. At the industry level, the life cycles of different vintages overlap each other (see Figure 3). Figures 4a-c provide evidence that the same pattern also holds at the firm level. They illustrate the evolution of shipments of different vintages over

\footnotetext{
${ }^{8}$ For detailed information regarding the production process of DRAMs, see also Flamm (1996).
} 
time for the 3 top-selling firms in the $64 \mathrm{~K}$ vintage: NEC, Texas Instruments and Hitachi, respectively. The figures clearly illustrate that firms simultaneously produce adjacent vintages. Hence, the figures support the notion that cannibalization effects might have an impact on the prices of adjacent vintages through substitution effects. Table 1 shows that the number of firms for different vintages varies from 12 to 23 firms and illustrates that the DRAM industry is characterized by an oligopolistic market structure. The table also shows that multiple consecutive vintages are offered by most of the firms in the DRAM industry. For instance, the 256K DRAM chip is sold by 23 firms, of which 16 firms produce both adjacent vintages, the $64 \mathrm{~K}$ as well as the 1MB DRAM chip. It is interesting to note that all 256K DRAM producers offer at least one further adjacent chip. Hence, the table confirms the fact that the DRAM industry is characterized by multi-vintage firms.

Our database consists of two parts. The first part, provided by Dataquest, describes quarterly firm-level shipments and average industry prices for different vintages beginning in 1974 for the $4 \mathrm{~K}$ vintage and ending in 1996 for the $1 \mathrm{MB}$ vintage. The second part consists of the GDP in electronics and electronic products and factor prices, i.e., wages, material and energy costs. The worldwide GDP $(G D P)$ is supposed to capture the overall activity in electronics (see Flamm, 1996) and controls for the downstream demand of electronics. The variable is constructed using the accumulated production of the five leading countries selling electronic products: USA, Japan, Germany, France, and the UK. ${ }^{9}$ The price of material (mat) is determined by the world market price of silicon and taken from the 'Metal Bulletin.' The remaining two firm-level factor prices, labor (lab) and energy $(e)$, vary considerably from country to country, and the variation in factor prices needs to be captured. We use the the proportion of plants that each firm operates in every country and interact those with the corresponding factor prices in these countries, i.e. USA, Japan, Germany, UK, Korea, and Taiwan. The labor costs for firm $i$, in period $t$,

\footnotetext{
${ }^{9}$ These five countries account for more than $90 \%$ of the worldwide production in electronics among the OECD countries. Missing data in the time series of other countries prevents us from including those countries.
} 
are collected for the semiconductor industry (ISIC 3825) and taken from the STAN Database, OECD (1998). The energy prices for firm $i$, in period $t$, are taken from the International Energy Agency/OECD (1998). Following Irwin and Klenow (1994) we also adjusted all factor prices using the producer price index.

Summary statistics and definitions of the variables are shown in Table 2. Focusing on the $256 \mathrm{~K}$ chip, the average price throughout the life cycle is US- $\$ 13.82$ with a maximum of US-\$196.13 and a minimum of US-\$1.27. A firm sells approximately 2.6 million chips per quarter, achieving a market share of approximately $11 \%$. 14 firms are present, on average, in the market, whereby the maximum number of firms is 19. These numbers confirm that the industry is characterized by an oligopolistic market structure.

\section{The Model}

In the following, we introduce the theoretical model, which represents the basis for the empirical model specification. We discuss the consequences on the measurement of learning-by-doing stemming from the inclusion of demand-side cannibalization effects.

We consider a game which is based on Fudenberg and Tirole (1983) and we follow the description by Fudenberg and Tirole (1986) and Vives (1999). An oligopolistic dynamic state-space game is modelled. We consider $n$ multi-vintage firms, indexed by $i=1 \ldots n$, offering subsequent vintages $k=1 \ldots K$, in $t=1 \ldots T$ discrete time periods. We assume products to be homogenous within a vintage itself, but differentiated across vintages.

Learning-by-doing effects are modelled as arguments, which enter the cost function. The industry-wide past production vector for vintage $k$ in period $t$ is represented by $X_{k, t} \equiv\left(x_{i, k, t}\right)_{i=1}^{n}$, where $x_{i, k, t} \equiv \sum_{\tau=1}^{t-1} q_{i, k, \tau}$ denotes firm $i$ 's past production for vintage $k$, and $q_{i, k, \tau}$ represents production of vintage $k$ in period $\tau$. The state for vintage $(k)$ evolves according to $X_{k, t}=X_{k, t-1}+Q_{k, t}$ where $Q_{k, t} \equiv\left(q_{i, k, t}\right)_{i=1}^{n}$ denotes the industry output vector and $X_{k, 0}=0$ states the initial condition, indicating 
that there is no experience at the beginning of the life cycle. ${ }^{10}$ With state-space games, past pay-off relevant choices that affect current profits are aggregated into a state-variable for each firm. Firms follow state-dependent (feedback or Markov) strategies, and choose actions depending on the state variables. Hence, firms decide on their future strategies at any point in time conditional on their past.

We account for learning from own past experience and other firms' past experience originating from vintage $(k)$ as well as the preceding vintage $(k-1)$. Moreover, firm $i$ 's costs are dependent on the contemporaneous firm-level output of vintage $(k)$ and the firm-level factor prices $W_{t}^{11}$

$$
C_{i}\left(q_{i, k, t}, W_{t} ; x_{i, k, t}, X_{-i, k, t} ; x_{i, k-1, t}, X_{-i, k-1, t}\right)
$$

The industry-wide past production for vintage $(k)$, excluding own past production, is denoted by $X_{-i, k, t} \equiv\left(x_{j, k, t}\right)_{j \neq i}$. Note that we also introduce firm-specific costs, indexed by the subscript $i$, allowing for heterogeneity between firms.

Each firm chooses quantities in order to maximize the discounted sum of profits over the entire product life cycle while using its state-dependent rules. The assumption that firms set quantities is in line with the previous literature and is also a reasonable assumption considering that every vintage represents a homogenous good in itself. Firm $i$ 's objective function is given by

$$
\begin{aligned}
\max _{\left\{q_{i, k, t}\right\}_{k=1}^{K}>0} \Pi_{i}= & \sum_{t=1}^{T} \sum_{k=1}^{K} \delta^{t-1}\left[P\left(q_{k, t} ; q_{k-1, t}, q_{k+1, t}\right) q_{i, k, t}\right. \\
& \left.-C_{i}\left(q_{i, k, t}, W_{t} ; x_{i, k, t}, X_{-i, k, t} ; x_{i, k-1, t}, X_{-i, k-1, t}\right)\right]
\end{aligned}
$$

where $\delta$ is the discount rate and $P\left(q_{k, t} ; q_{k-1, t}, q_{k+1, t}\right)$ is the inverse demand function for industry-wide demands $q_{\nu, t} \equiv \sum_{j=1}^{n} q_{j, \nu, t}$ for $\nu=k-1, k, k+1$. Note that beyond

\footnotetext{
${ }^{10}$ Accodingly, the state for vintage $(k-1)$ evolves according to $X_{k-1, t}=X_{k-1, t-1}+Q_{k-1, t}$.

${ }^{11}$ However, as mentioned above, we take into consideration that labor and energy varies between countries, and therefore between firms.
} 
vintage $k$, adjacent vintages $(k-1$ and $k+1)$ enter the inverse demand equation causing cannibalization effects. ${ }^{12}$ The fact that the price of vintage $k$ might be influenced by both adjacent vintages is supported by our data, as shown in Figures 3 and 4.

Next, we illustrate that substitution effects enter the supply side in a multivintage firm specification and may result in different learning estimates compared to a single-vintage specification. Firm $i^{\prime} s$ first-order conditions based on equation (1) with respect to the quantity of vintage $k$, is given by ${ }^{13}$

$$
\begin{aligned}
& P_{k, t}+\frac{\partial q_{k, t}}{\partial q_{i, k, t}}\left[\frac{\partial P_{k-1, t}}{\partial q_{k, t}} q_{i, k-1, t}+\frac{\partial P_{k, t}}{\partial q_{k, t}} q_{i, k, t}+\frac{\partial P_{k+1, t}}{\partial q_{k, t}} q_{i, k+1, t}\right]=\frac{\partial C_{i, k, t}}{\partial q_{i, k, t}} \\
& +\sum_{s=t+1}^{T} \delta^{s-t}\left\{\frac{\partial C_{i, k, s}}{\partial x_{i, k, s}} \frac{\partial x_{i, k, s}}{\partial q_{i, k, t}}+\frac{\partial C_{i, k, s}}{\partial X_{-i, k, s}} \frac{\partial X_{-i, k, s}}{\partial q_{i, k, t}}+\frac{\partial C_{i, k+1, s}}{\partial x_{i, k, s}} \frac{\partial x_{i, k, s}}{\partial q_{i, k, t}}+\frac{\partial C_{i, k+1, s}}{\partial X_{-i, k, s}} \frac{\partial X_{-i, k, s}}{\partial q_{i, k, t}}\right. \\
& -\left(\sum_{j \neq i}^{n} \frac{\partial q_{j, k, s}}{\partial C_{j, k, s}} \frac{\partial C_{j, k, s}}{\partial x_{j, k, s}} \frac{\partial x_{j, k, s}}{\partial q_{i, k, t}}+\sum_{j \neq i}^{n} \frac{\partial q_{j, k+1, s}}{\partial C_{j, k+1, s}} \frac{\partial C_{j, k+1, s}}{\partial x_{j, k, s}} \frac{\partial x_{j, k, s}}{\partial q_{i, k, t}}\right) \\
& \left.\times\left(\frac{\partial P_{k-1, s}}{\partial q_{k, s}} q_{i, k-1, s}+\frac{\partial P_{k, s}}{\partial q_{k, s}} q_{i, k, s}+\frac{\partial P_{k+1, s}}{\partial q_{k, s}} q_{i, k+1, s}\right)\right\}
\end{aligned}
$$

for $t<s$. The first line shows firm $i$ 's marginal profits in a static environment without learning effects. It shows the direct effect of firm $i$ 's output choice on its contemporaneous profits. The left-hand side of equation (2) represents firm $i$ 's marginal revenues and the expression $\frac{\partial q_{k, t}}{\partial q_{i, k, t}}$ indicates the conjectural variation term or the conduct parameter (see also Iwata, 1974; and Bresnahan, 1989). In comparing this to the standard marginal revenue term when only one vintage is considered in the market (single-vintage firm specification), beyond the own-price effects $\left(\frac{\partial P_{k, s}}{\partial q_{k, s}}\right)$,

\footnotetext{
${ }^{12}$ Note that we tested for robustness and allowed two adjacent vintages to enter the inverse demand equation, and two preceding vintages to enter firms' cost functions. Estimation results show that substitution effects beyond adjacent vintages are not having a significant impact, i.e., learning is not significant across two vintages. The estimation results are available from the author upon request.

${ }^{13}$ In order to better illustrate the interdependency between demand-side cannibalization across vintages and the measurement of learning effects, we focus on the firm's maximization problem for vintage $k$.
} 
further substitution effects $\left(\frac{\partial P_{k-1, t}}{\partial q_{k, t}}\right.$ and $\left.\frac{\partial P_{k+1, t}}{\partial q_{k, t}}\right)$ enter the pricing relation. When adjacent products are substitutes (complements), the effects are supposed to be negative (positive). The first line on the right-hand side of equation (2) represents the common contemporaneous or static marginal costs and indicates how current output affects current costs through economies of scale.

The following three lines of equation (2) show the dynamic link between firms' current output decisions and firms' environment they find themselves in, in the future, induced by learning. Firms account for intertemporal effects having an impact on their own and their rivals' unit costs and on future prices through learning. Note that we assume competitors in the future respond only to firms' current output choices in anticipation of cost advantages from industry-wide learning. Therefore, we ignore other strategic reasons that do not enter the cost function, such as preemption or dumping effects.

The first two terms in the second line of equation (2) represent firms' own learning and learning from others within a vintage $(k)$. They illustrate how firm $i^{\prime} s$ current output of vintage $k$ affects its own future costs for vintage $(k)$. The term $\frac{\partial C_{i, k, s}}{\partial x_{i, k, s}} \frac{\partial x_{i, k, s}}{\partial q_{i, k, t}}$ refers to the own learning effect within vintage $(k)$, indicating that own current output of vintage $k$ increases own experience and yields own cost savings in the future. The term is supposed to be negative. The term $\frac{\partial C_{i, k, s}}{\partial X_{-i, k, s}} \frac{\partial X_{-i, k, s}}{\partial q_{i, k, t}}$ represents learning from other firms within a vintage $(k)$. This expression shows that firm $i$ 's output decision in period $t$ increases other firms' experience in the future, having an impact on its own costs for vintage $k$ in the future. This effect measures by how much firm $i$ 's costs decline through capturing part of the rivals' experience.

The next two terms in the second line of equation (2) account for firms' own learning and learning from others across vintages. They illustrate how firm $i^{\prime}$ s current output of vintage $k$ affects its own future costs for vintage $(k+1)$. The specification corresponds to the two previous terms adjusted for cross-vintage effects.

The two terms in the third line of equation (2), in combination with the fourth line, indicate that firm $i$ is also aware of how its output decision of vintage $(k)$ affects future output as well as future prices of current and adjacent vintages. For 
example, the term $\frac{\partial q_{j, k, s}}{\partial C_{j, k, s}} \frac{\partial C_{j, k, s}}{\partial x_{j, k, s}} \frac{\partial x_{j, k, s}}{\partial q_{i, k, t}}$ represents a strategic intertemporal term, which indicates how firm $i$ 's output of vintage $k$ impacts the rivals' future output of vintage $k$ through learning within a vintage. The next term represents the same strategic intertemporal effect across vintages. These strategic intertemporal effects reflect the fact that firms follow no memory closed-loop strategies, i.e., firms condition their play at time $t$ on the history of the game until that date (see also Basar and Olsder, 1991). This therefore allows firms to adjust their output paths throughout the life cycle (opposed to precommitment or open-loop strategies). Consequently, the last two terms in the second line of equation (2) indicate that competitors' quantity responses are anticipated in an intertemporal fashion via achieving cost reductions through learning. The terms highlight the fact that firms follow feedback strategies in which they consider the strategic effect of their own output on their rivals' future output decision. ${ }^{14}$ Zulehner (2003) shows that the assumption that firms following no memory closed-loop strategies is appropriate for the semiconductor industry.

The last line of equation (2) shows that future own price effects and substitution effects enter firm $i$ 's pricing relation through the interaction with the strategic intertemporal term. Comparing the first-order condition of a multi-vintage specification with a single-vintage specification, shows that marginal revenues are determined by a further component, i.e., the substitution effects. Those are interacted with the conjectural variation term and the intertemporal strategic terms. Hence, multivintage firms are aware that increasing the production rate of vintage $k$ will have a current as well as an intertemporal impact on the prices and quantities demanded for adjacent vintages.

In the presence of learning, the output decisions by multi-vintage firms are characterized by the following trade-off: (i) raising a vintage's output achieves higher cost reductions in the future through learning, which induces firms to increase their output, and (ii) increasing a vintage's output cannibalizes the demand of other vintages. In a multi-vintage specification, firms anticipate the cannibalization effect in their production optimization. Hence, in a single-vintage specification, a further in-

\footnotetext{
${ }^{14}$ For existence of a Nash equilibrium with feedback strategies, see Basar and Olsder (1991).
} 
centive to decrease production to avoid cannibalization is ignored. Since cumulated output is used as a proxy for experience and adopted to measure learning effects, the inclusion of demand-side cannibalization effects results, ceteris paribus, in higher learning effects. The omission of the second effect attributes a lower production rate to the achievement of future cost reductions through learning. Our hypothesis which will be tested empirically is stated as follows:

A multi-vintage firm specification will result in higher estimated learning effects than a single-vintage specification, if vintages represent (imperfect) substitutes.

In the next section, we test our hypothesis by estimating a dynamic model consisting of demand and pricing relations, based on equation (2).

\section{The Empirical Model}

In order to test our hypothesis, we are interested in estimating a dynamic model consisting of demand and pricing equations. Since the number of firms in the industry is close to 20, the curse of dimensionality becomes a problem when solving for Markov Perfect Equilibria, and computing firms' value functions. ${ }^{15}$ Therefore, we will estimate the effects of interest from firms' first-order conditions. ${ }^{16}$ Building on the theoretical model from which we derived the supply relations for a multi-vintage firm specification, we specify our empirical model. ${ }^{17}$ Specifically, our model consists of three inverse demand functions from which we derive the corresponding own-price and substitution effects and firms' pricing relations, which are based on equation $(2)$.

\footnotetext{
${ }^{15}$ See also Pakes and McGuire (1994 and 2001) and Ericson and Pakes (1995).

${ }^{16}$ As the main focus of the paper is to highlight the potential mismeasurement of learning effects when ignoring demand-side cannibalization effects, the estimation from first-order conditions is an appropriate method since empirical counterfactuals are not relevant here. Note, that the estimation from first-order conditions does not require the computation of the firms' value functions.

${ }^{17}$ Our model specification is also related to Fudenberg and Tirole (1983) and Jarmin (1994).
} 


\subsection{The Inverse Demand Functions}

The inverse demand functions are given by ${ }^{18}$

$$
\begin{aligned}
P_{k-1, t}= & a_{0}+a_{1} * q_{k-2, t}+a_{2} * q_{k-1, t}+a_{3} * q_{k, t} \\
& +a_{4} * G D P_{t}+\varepsilon_{k-1, t} \\
P_{k, t}= & b_{0}+b_{1} * q_{k-1, t}+b_{2} * q_{k, t}+b_{3} * q_{k+1, t} \\
+ & b_{4} * G D P_{t}+\mu_{k, t} \\
P_{k+1, t}= & c_{0}+c_{1} * q_{k, t}+c_{2} * q_{k+1, t}+c_{3} * q_{k+2, t} \\
& +c_{4} * G D P_{t}+\omega_{k+1, t} .
\end{aligned}
$$

For the sake of convenience, let us consider the inverse demand equation (4) only; the same rationale applies to equations (3) and (5). As can be seen in equation (4), the price $P_{k, t}$ depends on the industry output of the vintage under consideration $\left(q_{k, t}\right)$, as well as the industry output of the adjacent vintages $q_{k-1, t}$ and $q_{k+1, t}$. The worldwide GDP in electronics and electronic products $\left(G D P_{t}\right)$ is incorporated into our model as a demand shifter. The coefficient $b_{2}$ indicates the own-price effect. The sign is expected to be negative, for a higher output results in lower prices. The coefficients $b_{1}$ and $b_{3}$ refer to the substitution effects and are supposed to be negative (positive) when adjacent products are substitutes (complements). From the estimation of the inverse demand equations (3), (4), and (5), we obtain the corresponding price effects, given by the estimated coefficients $\widehat{a_{3}}, \widehat{b_{2}}$, and $\widehat{c_{1}}$, which are plugged into the pricing relation in the second stage.

\subsection{The Pricing Relations}

Solving the first-order equation (2) for price as a function of output and dynamic marginal costs, gives us the following pricing relation, which will be estimated

\footnotetext{
${ }^{18}$ The specification of the inverse demand functions is in line with the study by Flamm (1996) in which adjacent vintages enter the equations.
} 


$$
\begin{aligned}
& P_{k, t}=\alpha_{0, i}+\alpha_{1} \ln X_{i, k, t}+\alpha_{2} \ln X_{-i, k, t}+\alpha_{3} \ln X_{i, k-1, t}+\alpha_{4} \ln X_{-i, k-1, t}+\alpha_{5} \ln q_{i, k, t} \\
& +\alpha_{6} \ln \text { mat }_{t}+\alpha_{7} \ln l a b_{i, t}+\alpha_{8} \ln e_{i, t}+\alpha_{9} D_{y n} \text { Effect }_{i, k, t}-\alpha_{10} P E_{i, k, t}+\nu_{i, k, t} .
\end{aligned}
$$

As described above, firms' dynamic marginal costs are composed of the static marginal costs, represented by the term $\frac{\partial C_{i, k, t}}{\partial q_{i, k, t}}$ in equation (2), and the dynamic effects which yield future cost reductions through learning, as shown in the second and the consecutive lines of equation (2).

Firms' static marginal costs are empirically specified by accounting for the following aspects. We include firm specific effects $\bar{\alpha}_{0, i}$ in order to capture any unobserved heterogeneity in the cost function. ${ }^{19}$ We account for own learning-by-doing within a vintage by incorporating the variable $X_{i, k, t}$ which represents firm $i$ 's experience in production for vintage $k$. The variable is constructed by taking the accumulated past production of firm $i$ until period $t-1$. We also account for learning effects within a vintage that firms gain from their rivals' experience through spillovers, measured by the variable $X_{-i, k, t}$ which is constructed by taking the accumulated past production of vintage $k$ of all firms until period $t-1$. The variables $X_{i, k-1, t}$ and $X_{-i, k-1, t}$ are supposed to capture learning from own experience and other firms' experience from vintage $k-1$. The construction of those variables follows the same rationale as for vintage $k$. The signs of coefficients $\alpha_{1}$ to $\alpha_{4}$ are supposed to be negative if the specific type of learning reduces marginal costs. We also control for static economies of scale effects measured by $q_{i, k, t}$, i.e., firm $i$ 's current output of vintage $k$ in period $t$. The scale effect is negative, zero, or positive, when increasing, constant, or decreasing returns are prevalent. ${ }^{20}$ We also use the following factor prices: the price of material or silicon $\left(\right.$ mat $\left._{t}\right)$, labor $\left(l a b_{i, t}\right)$ and energy $\left(e_{i, t}\right)$.

\footnotetext{
${ }^{19}$ Note that the coefficient $\alpha_{0, i}=\bar{\alpha}_{0, i}+\widehat{\alpha}_{0, i}$ in equation (6) controls for firm-specific effects, where $\bar{\alpha}_{0, i}$ stems from the static marginal cost function and $\widehat{\alpha}_{0, i}$ is supposed to capture remaining unobserved heterogeneities.

${ }^{20}$ Considering both, learning and economies of scale effects together, is necessary for both to influence each other. The existence of economies of scale results in a contemporaneous unit cost decline by increasing output. Ignorance of scale coincides with an inappropriate omission of the current output variable which impacts the learning effects. The cost reduction effect is exclusively
} 
As learning also induces a dynamic aspect through which future cost reductions are achieved we have to account for the fact that firms may price below their static marginal costs in order to gain cost savings in the future. The problem is that the dynamic part of the mark-up is complicated, and computing the value function is difficult due to the large number of firms. Alternatively, we could estimate the dynamic effect. The problem, however, is that the model would not be identified if all terms that measure the dynamic effects are estimated, as they vary over all 3 subindexes $i, k$, and $t$. Consequently, the dynamic effects cannot be identified separately from the static mark-up. However, we must control for firms' stages within the life cycle, in order to account for the fact that firms optimize their intertemporal production plans. We enable the estimation procedure and identify the dynamic effects by making a functional form assumption. We capture the firm-specific dynamic effects by introducing a firm-specific time trend $\left(D y n_{-} E f f e c t_{i, k, t}\right)$. This trend controls for number of remaining periods in the life cycle of vintage $k$. It captures future potential cost savings at the firm-level depending on the period within the life cycle.

Finally, the $P E$ variable represents $\left[\frac{\partial P_{k-1, t}}{\partial q_{k, t}} q_{i, k-1, t}+\frac{\partial P_{k, t}}{\partial q_{k, t}} q_{i, k, t}+\frac{\partial P_{k+1, t}}{\partial q_{k, t}} q_{i, k+1, t}\right]$ from the first line of equation (2), where the own-price effect $\frac{\partial P_{k, t}}{\partial q_{k, t}}$ as well as the substitution effects $\frac{\partial P_{k-1, t}}{\partial q_{k, t}}$ and $\frac{\partial P_{k+1, t}}{\partial q_{k, t}}$ will be replaced with the estimated coefficients $\widehat{b_{2}}$, $\widehat{a_{3}}$, and $\widehat{c_{1}}$, respectively, from the inverse demand equation. We assume that firms behave like Cournot players and set the conduct parameter equal to one. The estimation procedure will be explained in Section 5.

\section{Results}

As the pricing relations will be estimated for the $256 \mathrm{~K}$ DRAM vintage $(k)$, we need to estimate the inverse demand equations for the $256 \mathrm{~K}$ DRAM vintage $(k)$, as well as for the $64 \mathrm{~K}$ DRAM and 1MB DRAM vintages $(k-1$ and $k+1$, respectively). We assume

attributed to the learning curve, though part of it is in fact due to the presence of economies of scale: an omitted variable bias will occur (see Berndt, 1991). 
additive econometric disturbances which have a mean of zero and a covariance matrix $\Phi$. Since aggregate firms' (or industry) outputs for the vintage under consideration might be correlated with the error term, we need to use instruments in order to identify the demand elasticity. We use factor prices as instruments, i.e., material (silicon), wages and energy, that capture the shifts of marginal costs on the supply side. Moreover, we capture changes in the degree of competitiveness in the product market by accounting for summary statistics from the supply side, such as the number of firms present in the market. We also use a time trend indicating the length of time a vintage has been in the market. ${ }^{21}$ The inverse demand functions (3), (4), and (5) are estimated using 2 stage least squares using the Newey and West (1987) heteroskedasticity and autocorrelation consistent covariance matrix.

The estimation results for the inverse demand equations (3), (4), and (5) are presented in Table 3. In the estimation procedures 68, 57, and 46 observations have been used for vintages $k-1, k$, and $k+1$, respectively. All three estimations have a remarkably good fit. The adjusted R-squares are 0.72 and higher, and all own-price effects are significant at the $1 \%$ level. The own-price effects carry the expected negative sign, indicating that a higher industry output decreases prices. Calculating the corresponding own-price elasticities by using the estimated price effects evaluated at the sample means of prices and quantities, results in elasticities of around -1, which is close to what previous studies found, see e.g., Flamm (1993b), Irwin and Klenow (1994) and the literature cited therein, and Zulehner (2003). The substitution effects are significant at least at the $10 \%$ level, with $c_{3}$ being the only exception. The negative estimates show that adjacent vintages represent substitutable products and indicate that cannibalization effects are prevalent on the demand side.

Turning to the multi-vintage firm pricing relation, we instrument for firms' contemporaneously chosen outputs, as well as own learning and learning from other firms within vintages. As instruments, we use the GDP as a demand shifter and

\footnotetext{
${ }^{21}$ The time trend could also be interpreted as a proxy for intertemporal price discrimination among consumers.
} 
lagged endogenous variables as well as summary statistics that reflect the competitiveness in the market, such as the number of firms and average market shares. ${ }^{22} \mathrm{We}$ impose the same restrictions on econometric disturbance terms as above and use the same two-stage least squares procedure as for the inverse demand equations. The estimates of the multi-vintage firm pricing relation are shown in Table 4, columns 2 and 3. We use 611 observations in our estimations, which have a very good fit. The adjusted R-square is 0.58 . Most of the parameter estimates are significant at the $1 \%$ level. The coefficient $\alpha_{1}$ measures the effect of own learning within a vintage $\left(X_{i, k, t}\right)$ on marginal costs. As the results show, the estimate is highly significant and negative. Evaluating the learning elasticity at the respective sample mean and correcting for the semilog specification, amounts to a learning elasticity of -0.341 , which corresponds to a $20.9 \%$ learning rate. The learning rate is calculated by using the formula $1-2^{\alpha}$, where $\alpha$ represents the learning elasticity. Hence, a doubling in a firm's accumulated output of vintage $k$ (at the sample mean) reduces marginal costs of the corresponding vintage by $20.9 \%$. This estimate is similar to what the engineering literature claims.

We also estimate a single-vintage specification as a benchmark case, which follows the same specification as the multi-vintage firm specification with the exception that substitution effects are set equal to zero, such that no cannibalization effects enter the pricing relation. The results are shown in Table 4, columns 4 and 5. The adjusted R-square is 0.56 . The single-vintage specification returns a learning rate of $11.7 \%$. This finding confirms our hypothesis that a multi-vintage firm specification returns a higher learning-by-doing estimate than a single-vintage specification. To summarize, a multi-vintage firm specification captures the trade-off between increasing output in order to gain cost savings due to learning, and reducing output in order to diminish cannibalization effects on adjacent vintages. The latter effect is ignored by econometricians, resulting in too low of a production incentive that is referred to learning-by-doing.

\footnotetext{
${ }^{22}$ For a more detailed discussion on regaining consistency when accumulated output is correlated with the error term, see e.g., Olley and Pakes (1996).
} 
In order to test if the learning estimates between the single- and multi-vintage specification are statistically different from each other, it is useful to generate the complete distribution of the estimators. In order to test for significance between the learning estimates we use bootstrap methods. The advantage with bootstrapping is that we do not need to know the type of distribution from which a sample has been taken. We use a non-parametric bootstrap method (with replacement) as suggested by Efron (1982) and generate 1,000 bootstrap samples of the same size as the original dataset, which makes up to 611,000 observations in total and estimate the learning estimates for each bootstrap sample. ${ }^{23}$ The bootstrap samples are used in order to test whether the learning estimates are statistically different from each other. Using a test of $H_{0}: \widehat{a}_{4}^{m}=\widehat{a}_{4}^{s}$ against $H_{a}: \widehat{a}_{4}^{m} \neq \widehat{a}_{4}^{s}$ and applying the percentile interval method, we compare the estimated learning rates with the percentile value in the sampled dataset. ${ }^{24}$ Our test statistic shows that we can reject $H_{0}$ approximately at the $10 \%$ level.

Our results also confirm significant own learning effects across vintages $\left(X_{i, k-1, t}\right)$. This finding indicates that a higher degree of past experience for vintage $k-1$ reduces marginal costs for vintage $k$. Our estimation of the multi-vintage specification, returns a learning rate of $12.7 \%$. The single-vintage specification returns a very similar learning rate of $12.2 \%$. Interestingly, the learning effects across vintages are only about half as large as the learning effects within vintages. The finding of learning across vintages (or intergenerational spillovers) also supports the results by Irwin and Klenow (1994). As mentioned above, we performed robustness checks with regard to learning across vintages. Hence, we estimated specifications in which two preceding vintages enter the cost function and (accordingly) two adjacent vintages enter the inverse demand equation. The estimation results confirm that knowledge fully depreciates after one generation. For example, the experience of producing the $64 \mathrm{~K}$ chip contributes to the knowledge of producing the $256 \mathrm{~K}$ chip, but it does not

\footnotetext{
${ }^{23}$ For tests at a 0.05 significance level, Efron (1993) and Davidson and MacKinnon (2000) recommend 200 and 399 samples, respectively.

${ }^{24}$ Note that $\widehat{a}_{4}^{m}$ and $\widehat{a}_{4}^{s}$ represent the own-learning estimates within vintages for the multi- and the single-vintage specification, respectively.
} 
benefit the production process of any successive vintage.

Learning from others is significant across vintages and amounts to $12.2 \%$. The learning rate from own experience is similar in magnitude to the learning rate from other firms' experience. We do not find significant learning effects from others within vintages. This result supports the fact that knowledge from competitors takes time to be absorbed and to be implemented into current production processes. We also applied different robustness checks and get similar results.

The estimate for the economies of scale effects $\left(q_{i, k, t}\right)$ is significant and positive, indicating that decreasing static returns to scale are evident. The significant estimate of the coefficient $\alpha_{9}$, indicates that firms further increase quantities in order to benefit from future cost reductions. The coefficients for the factor prices (except energy) are positive, which is meaningful since higher factor prices are supposed to raise firms' marginal costs.

\section{Conclusion}

This study demonstrates the importance of accounting for demand-side cannibalization effects and illustrates its impact on the measurement of learning-by-doing. Once demand-side cannibalization effects are accounted for, firms face a trade-off in determining the optimal production rate. On the one hand an increase in production will gain future cost savings through learning-by-doing. On the other hand, firms anticipate a disincentive to increase production, as cannibalization effects reduce the demand for the other vintages. Accounting for demand-side cannibalization effects attributes a higher production incentive to the measurement of learning effects, resulting in higher estimated learning effects.

Our results show that adjacent DRAM vintages represent (imperfect) substitutes. We can confirm that learning-by-doing effects are estimated higher in a multi-vintage specification. The learning rates within vintages are estimated to be $20.9 \%$ opposed to a learning rate of $11.7 \%$ in a single-vintage firm specification.

The adequate measurement of learning-by-doing effects is relevant for evaluating 
industrial policies as well as understanding the evolution of market structure and industry growth. Higher estimated learning effects within vintages may have crucial implications on firms' optimal production plans. For example, being aware of a higher learning effect provides larger incentives to further increase contemporaneous output in order to benefit from future cost reductions. Moreover, higher learning effects provide additional incentives for firms to introduce new products early in order to gain a headstart in moving down the learning curve, and to gain cost advantages to their competitors. ${ }^{25}$

The finding is also important from a policy's point of view. Accounting for cannibalization effects on the demand side might be relevant for the decision whether to provide subsidies to single- or multi-vintage firms. For example, if adjacent vintages are close substitutes, we may expect the promotion of single-vintage firms to be beneficial, as those do not face a disincentive to increase production in order to avoid cannibalization effects. On the other hand, promoting multi-vintage firms might be beneficial if learning effects across vintages are sufficiently high such that the benefits gained from learning across vintages compensates the negative effects arising from the disincentive to increase production in order to avoid cannibalization effects. It is worth mentioning that the adoption of new vintages in combination with persistence of consumption might result in a similar price pattern as shown in Figure 2. For future research it might be worth it to examine to what extent the rapid price declines are due to the fact that firms drastically reduce prices in order to make new products more attractive to consumers.

Our learning estimates across vintages are $12.7 \%$. It is interesting to note that the learning rate across vintages is only about half the size of the learning rates within vintages. Moreover, the learning estimates from own experience are not different from the learning rates across firms. The finding of learning-by-doing across vintages may provide incentives to continue keeping previous vintages in the market in order to capture further learning effects across vintages.

\footnotetext{
${ }^{25}$ Those aspects are beyond the scope of the paper and need to be elaborated in more detail in future research.
} 


\section{References}

Aizcorbe, A. and S. Kortum, 2005, "Moore's Law and the Semiconductor Industry: A Vintage Model," Scandinavian Journal of Economics, Vol. 107, No. 4, pp. 603-630.

Anderson, S.P., A. de Palma, and J.-F. Thisse, 1992, Discrete Choice Theory of Product Differentiation, MIT Press, Cambridge.

Argote, L. and S. Beckman, and D. Epple, 1990, "The Persistence and Transfer of Learning in Industrial Settings," Management Science, Vol. 36, pp. 140-154.

Basar, T. and G. Olsder, 1991, Dynamic Noncooperative Game Theory, Academic Press, London, Second Edition.

Benkard, C.L., 2000, "Learning and Forgetting: The Dynamics of Aircraft Production," American Economic Review, Vol. 90, No. 4, pp. 1034-1054.

Berndt, E., 1991, The Practice of Econometrics: Classic and Contemporary, AddisonWesley Publishing Company.

Berry, S., 1994, "Estimating Discrete-Choice Models of Product Differentiation", Rand Journal of Economics, Vol. 25, pp. 242-262.

Berry, S., J. Levinsohn and A. Pakes, 1995, "Automobile Prices in Market Equilibrium," Econometrica, Vol. 63, pp. 841-889.

Bresnahan, T.F., 1987, "Competition and Collusion in the American Auto Industry: The 1955 Price War," Journal of Industrial Economics, Vol. 35, pp. 457-482.

Bresnahan, T.F., 1989, Empirical Studies of Industries with Market Power, in: R. Schmalensee and R.D: Willig, eds. Handbook of Industrial Organization, Amsterdam: North Holland, 1989.

Cohen, W. and D. Levinthal, 1989, "Innovation and Learning: The Two Faces of R \& D," The Economic Journal, Vol. 99, pp. 569-596.

Cohen, W. and D. Levinthal, 1990, "Absorptive Capacity: A New Perspective on Learning and Innovation," Administrative Science Quarterly, Vol. 35, pp. $128-152$.

Dataquest, 1996, Semiconductor Database provided by Dataquest.

Davidson, R. and J. MacKinnon, 2000, "Bootstrap Tests: How Many Bootstraps?," Econometric Review, Vol. 19, pp. 55-68.

Dick, A.R., 1991, "Learning by Doing and Dumping in the Semiconductor Industry," Journal of Law and Economics, Vol. 34, pp. 133-159. 
Efron, B., 1982, The Bootstrap and other Resampling Plans, Society for Industrial and Applied Mathematics.

Efron, B. and J. Tibsharani, 1993, An Introduction to the Bootstrap, London: Chapman and Hall.

Ericson, R. and A. Pakes, 1995, "Markov-Perfect Industry Dynamics: A Framework for Empirical Work," Review of Economic Studies, Vol. 62, pp. 53-82.

Flamm, K., 1993a, "Forward Pricing vs Fair Value: An Analytical Assessment of 'Dumping' in DRAMs," in: Takatoshi Ito and Anne O. Krueger eds. Trade and Protectionism, Chicago and London, Chicago University Press, pp. 47-94.

Flamm, K., 1993b, "Measurement of DRAM Prices: Technology and Market Structure," in: M. Foss, M. Manser, and A. Young, eds. Price Measurement and their Uses, University of Chicago Press.

Flamm, K., 1996, Mismanaged Trade? Brookings Institution Press, Washington, D.C.

Fudenberg, D. and J. Tirole, 1983, "Learning by Doing and Market Performance," Bell Journal of Economics, Vol. 14, pp. 522-530.

Fudenberg, D. and J. Tirole, 1986, Dynamic Models of Oligopoly, Harwood Academic Publishers, Switzerland.

Fudenberg, D. and J. Tirole, 1991, Game Theory, MIT Press.

Ghemawat, P., 1985, "Building Strategy on the Experience Curve," Harvard Business Review, Vol. 63, pp. 143-149.

Ghemawat, P. and A.M. Spence, 1985, "Learning Curve Spillovers and Market Performance," Quarterly Journal of Economics, Vol. 100, pp. 839-852.

Goldberg, P.K., 1995, "Product Differentiation and Oligopoly in International Markets: The Case of the U.S. Automobile Industry," Econometrica, Vol. 63, pp. 891-951.

Gruber, H., 1992, "The Learning Curve in the Production of Semiconductor Memory Chips," Applied Economics, Vol. 24, pp. 885-894.

Gruber, H., 1996, "Trade Policy and Learning by Doing: The Case of Semiconductors," Research Policy, Vol. 25, pp. 723-739.

Gruber, H., 1998, "Learning by Doing and Spillovers: Further Evidence from the Semiconductor Industry," Review of Industrial Organization, Vol. 13, No. 6, pp. 697-711. 
Hall, B.H. and R.H. Ziedonis, 2001, "The Patent Paradox Revisited: An Empirical Study of Patenting in the US Semiconductor Industry, 1979-95," Rand Journal of Economics, Vol. 32, No. 1, pp. 101-128.

Hatch N.W. and D.C.Mowery, 1998, "Process Innovation and Learning by Doing in Semiconductor Manufacturing," Management Science, Vol. 44, No. 11, pp. 1461-1477.

Heiman, A., B. McWilliams, Z. Shen, and D. Zilberman, 2001, "Learning and Forgetting: Modeling Optimal Product Sampling Over Time," Management Science, Vol. 47, pp. 532-546.

Heskett, J., 1976, Marketing, New York: Macmillan.

Irwin, D. and P. Klenow, 1994, "Learning by Doing Spillovers in the Semiconductor Industry," Journal of Political Economy, Vol. 102, pp. 1200-1227.

Iwata, G., 1974, "Measurement of Conjectural Variations in Oligopoly," Econometrica, Vol. 42, pp. 947-966.

Jarmin, R.S., 1994, "Learning by Doing and Competition in the Early Rayon Industry," Rand Journal of Economics, Vol. 25, pp. 441-454.

Jorgenson, D.W., 2001, "Information Technology and the U.S. Economy," American Economic Review, Vol. 91, No. 1, pp. 1-32.

Jorgenson, D.W. and K. Vu, 20005, "Information Technology and the World Economy," Scandinavian Journal of Economics, Vol. 107, No. 4, pp. 631-650.

Lieberman, M.B., 1982, The Learning Curve, Pricing, and Market Structure in the Chemical Processing Industries, in: Ph.D. Dissertation, Harvard University.

Lieberman, M.B., 1984, "The Learning Curve and Pricing in the Chemical Processing Industries," Rand Journal of Economics, Vol. 15, pp. 213-228.

Majd, S. and R. Pindyck, 1989, "The Learning Curve and Optimal Production Under Uncertainty," Rand Journal of Economics, Vol. 20, pp. 331-343.

Miravete, E., 2003, "Time-Consistent Protection with Learning by Doing," European Economic Review, Vol. 47, pp. 761-790.

Moorthy, K.S. and I.P.L. Png, 1992, "Market Segmentation, Cannibalization, and the Timing of Product Introductions," Management Science, Vol. 38, No. 3, pp. 345-359.

Mussa, M. and S. Rosen, 1978, "Monopoly and Product Quality," Journal of Economic Theory, Vol. 18, No. 2, pp. 301-317. 
Newey, W.K. and K.D. West, 1987, "A Simple, Positive Semi-Definite, Heteroskedasticity and Autocorrelation Consistent Covariance Matrix," Econometrica, Vol. 55, No. 3, pp. 819-847.

Norton, J.A. and F.M. Bass, 1987, "A Diffusion Theory Model of Adoption and Substitution for Successive Generations of High-Technology Products," Management Science, Vol. 33, No. 9, pp. 1069-1086.

Nye, W.W., 1996, "Firm-Specific Learning-by-Doing in Semiconductor Production: Some Evidence from the 1986 Trade Agreement," Review of Industrial Organization, Vol. 11, pp. 383-394.

OECD/IEA, 1998, "Energy Prices and Taxes, International Energy Agency, First Quarter to Fourth Quarter, 1984- 1998," Paris.

OECD, 1998, STAN DATABASE, 1998, Paris.

Olley, G.S. and A. Pakes, 1996, "The Dynamics of Productivity in the Telecommunications Equipment Industry," Econometrica, Vol. 64, pp. 1236-1298.

Pakes, A. and P. McGuire, 1994, "Computing Markov Perfect Equilibria: Numerical Implications of a Dynamic Differentiated Product Model," Rand Journal of Economics, Vol. 25, pp. 555-589.

Pakes, A. and P. McGuire, 2001, "Stochastic Approximation for Dynamic Models: Markov Perfect Equilibrium and the 'Curse' of Dimensionality," Econometrica, Vol. 69, No. 5, pp. 1261-1281.

Song, M., 2007, "Measuring Consumer Welfare in the CPU Market: An Application of the Pure Characteristics Demand Model," RAND Journal of Economics, Vol. 38, pp. 429-446.

Spence, A.M., 1981, "The Learning Curve and Competition," Bell Journal of Economics, Vol. 12, pp. 49-70.

Stokey, N., 1988, "Learning by Doing and the Introduction of New Goods," Journal of Political Economy, Vol. 96, pp. 701-717.

Thornton, R. and P. Thompson, 2001, "Learning from Experience and Learning from Others: An Exploration of Learning and Spillovers in Wartime Shipbuilding," American Economic Review, Vol. 91, pp. 1350-1368.

Urban, G. L., P L. Johnson and J. R. Hauser, 1984, "Testing Competitive Market Structures," Marketing Science, Vol. 3, No. 2, pp. 83-112.

Verboven, F., 1996, "International Price Discrimination in the European Car Market," Rand Journal of Economics, Vol. 27, pp. 240-268.

Vives,. X., 1999, Oligopoly Pricing, MIT. 
Wright, T.P., 1936, "Factors affecting the Cost of Airplanes," Journal of Aeronautical Sciences, Vol. 3, pp. 122-128.

Zulehner, C., 2003, "Testing Dynamic Oligopolistic Interaction: Evidence from the Semiconductor Industry," International Journal of Industrial Organization, Vol. 21, pp. 1527-1556. 


\section{Appendix: Figures and Tables}

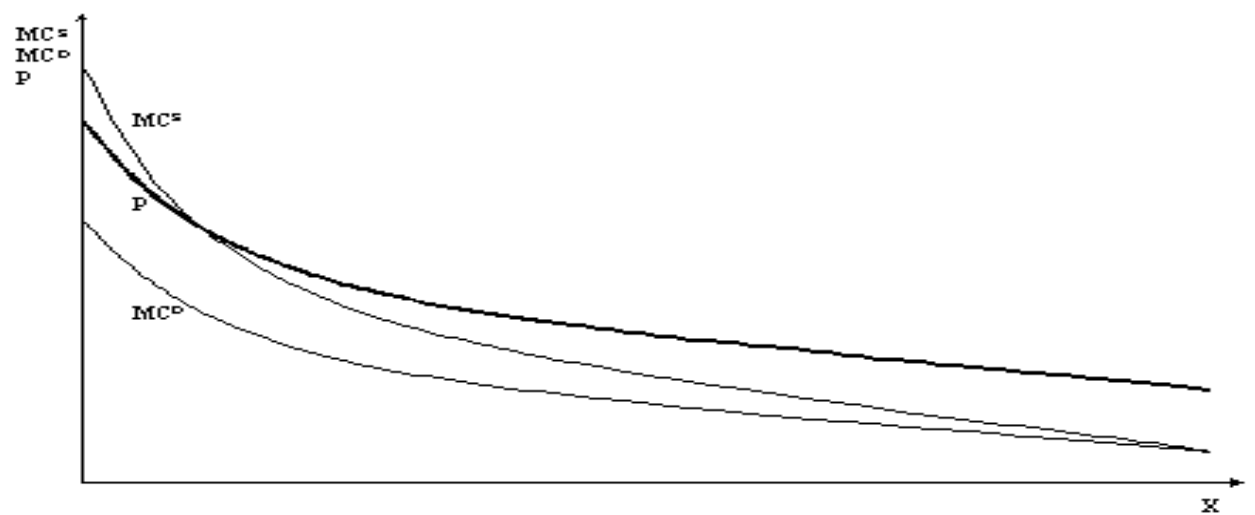

Figure 1: Price setting with respect to shadow marginal costs. Source: Dick (1991).

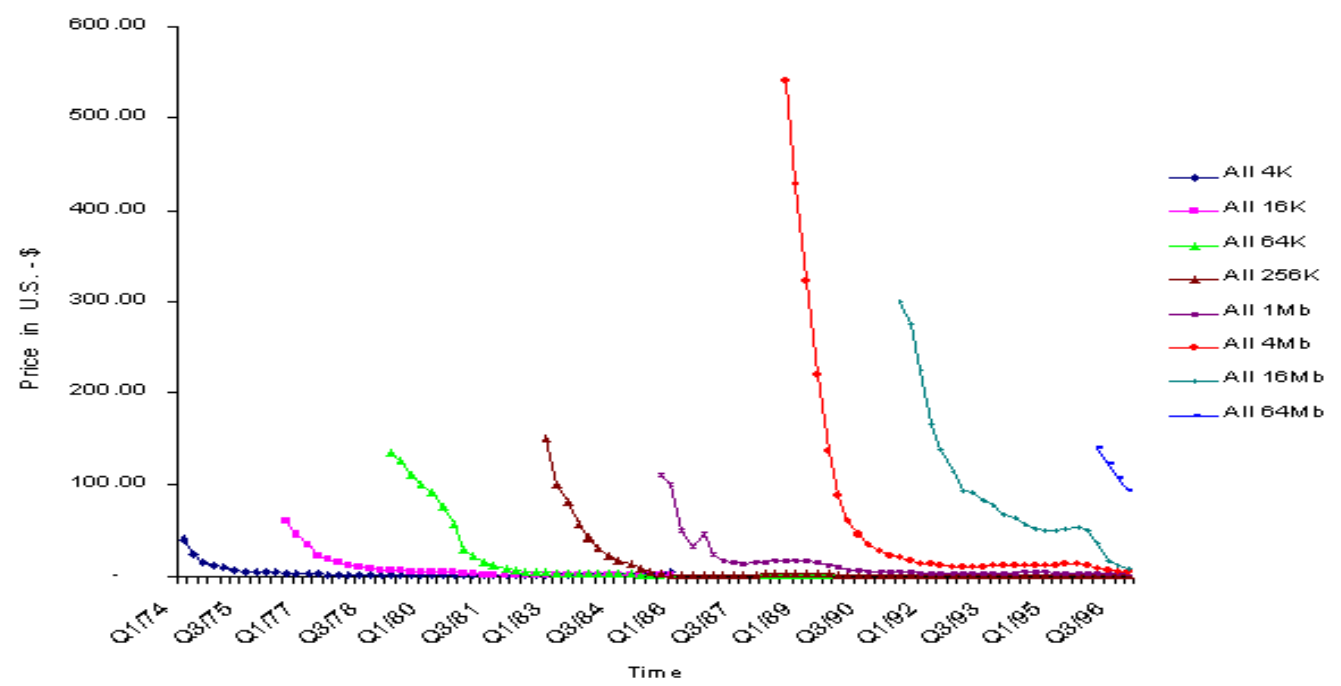

Figure 2: Price decline per generation over time. Source: Dataquest (1996). 


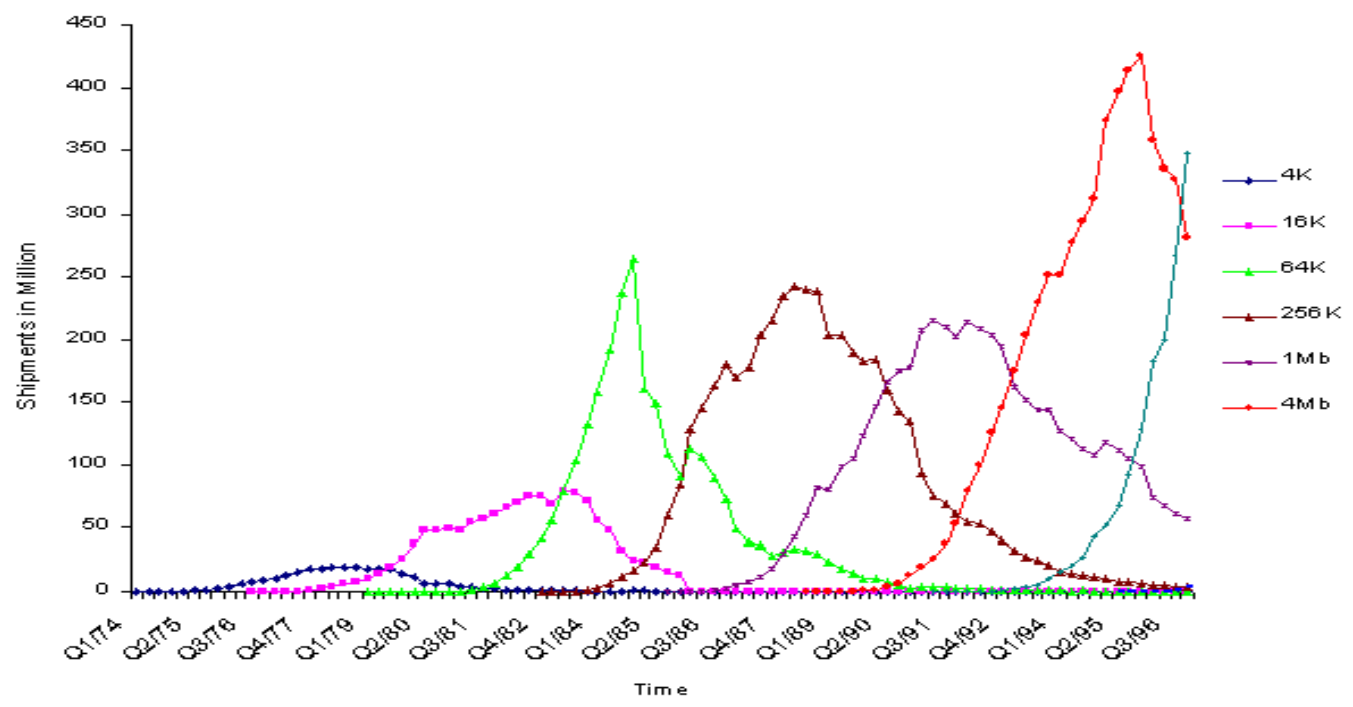

Figure 3: Units of shipments (millions) per generation. Source: Dataquest (1996).

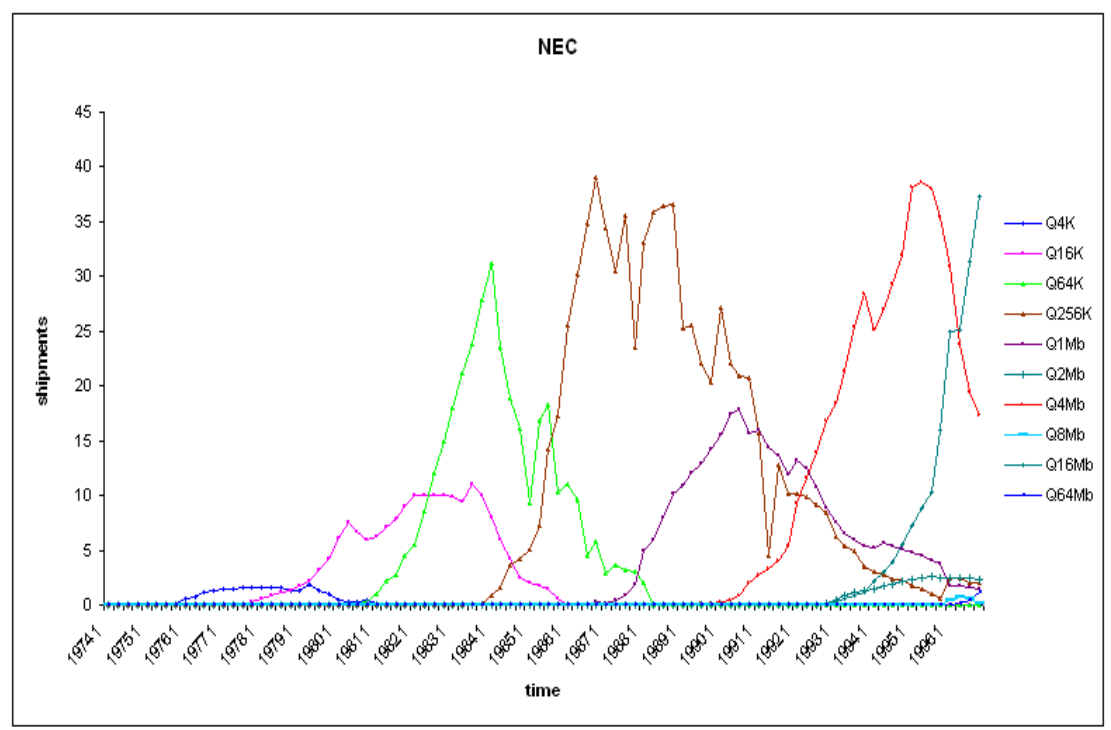

Figure 4a: NEC's shipments (in millions). Source: Dataquest (1996). 


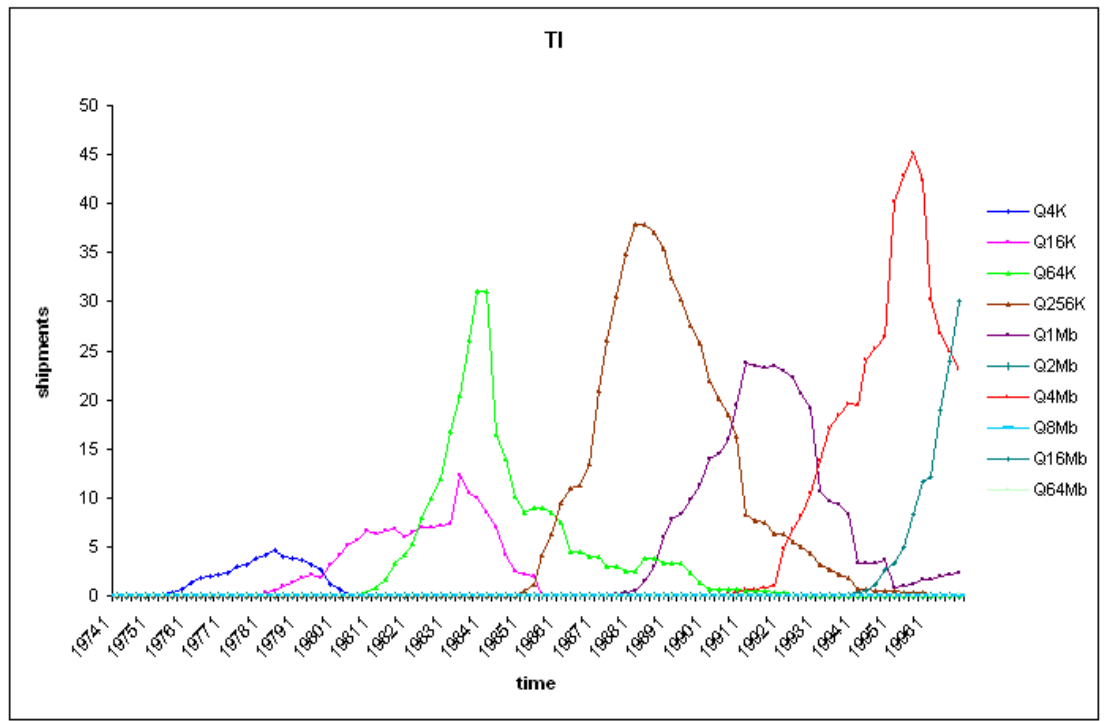

Figure 4b: Texas Instruments's shipments. Source: Dataquest (1996).

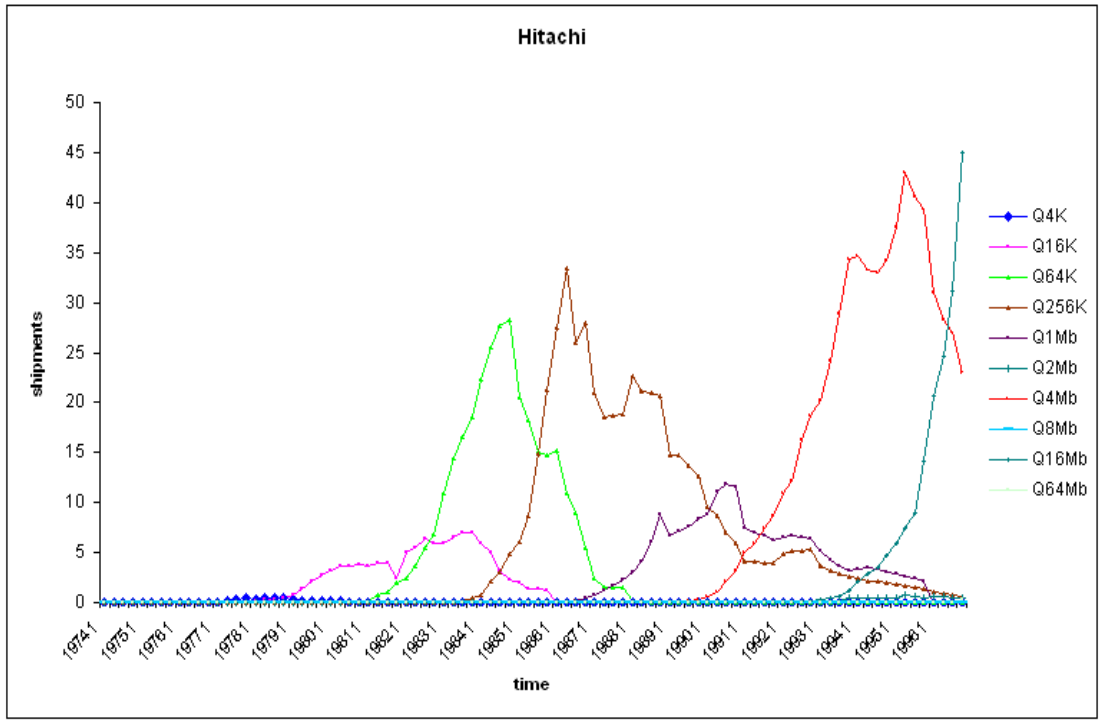

Figure 4c: Hitachi's shipments (in millions). Source: Dataquest (1996). 
Table 1: Production of generations in the DRAM industry, 1974-1996

\begin{tabular}{|c|c|c|c|c|c|c|c|c|c|}
\hline Firms & Gener. & $4 \overline{\mathrm{K}}$ & $\overline{c 16 \mathrm{~K}}$ & "64K & $256 \mathrm{~K}$ & $1 \mathrm{IMb}$ & 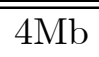 & $\bar{~} 16 \mathrm{Mb}$ & $64 \mathrm{Mb}$ \\
\hline Adv. Micro Dev. & 3 & $\mathrm{x}$ & $\mathrm{x}$ & $\mathrm{x}$ & . & . & . & . & . \\
\hline Alliance & 1 & . & . & . & . & . & $\mathrm{x}$ & . & . \\
\hline Am. Microsyst. & 1 & $\mathrm{x}$ & . & . & . & . & . & . & . \\
\hline AT\&T & 2 & . & . & . & $\mathrm{x}$ & $\mathrm{x}$ & . & . & . \\
\hline Eurotechnique & 1 & . & $\mathrm{x}$ & . & . & . & . & . & . \\
\hline Fairchild & 3 & $\mathrm{x}$ & $\mathrm{x}$ & $\mathrm{x}$ & . & . & . & . & . \\
\hline Fujitsu & 8 & $\mathrm{x}$ & $\mathrm{x}$ & $\mathrm{x}$ & $\mathrm{x}$ & $\mathrm{x}$ & $\mathrm{x}$ & $\mathrm{x}$ & $\mathrm{x}$ \\
\hline G-Link & 2 & . & . & . & . & $\mathrm{x}$ & $\mathrm{x}$ & & . \\
\hline Hitachi & 8 & $\mathrm{x}$ & $\mathrm{x}$ & $\mathrm{x}$ & $\mathrm{x}$ & $\mathrm{x}$ & $\mathrm{x}$ & $\mathrm{x}$ & $\mathrm{x}$ \\
\hline Hyundai & 6 & . & . & $\mathrm{x}$ & $\mathrm{x}$ & $\mathrm{x}$ & $\mathrm{x}$ & $\mathrm{x}$ & $\mathrm{x}$ \\
\hline IBM & 4 & . & . & . & . & $\mathrm{x}$ & $\mathrm{x}$ & $\mathrm{x}$ & $\mathrm{x}$ \\
\hline Inmos & 2 & . & . & $\mathrm{x}$ & $\mathrm{x}$ & . & . & . & . \\
\hline Intel & 5 & $\mathrm{x}$ & $\mathrm{x}$ & $\mathrm{x}$ & $\mathrm{x}$ & $\mathrm{x}$ & . & . & . \\
\hline Intersil & 2 & $\mathrm{x}$ & $\mathrm{x}$ & . & . & . & . & . & . \\
\hline LG Semicon & 5 & . & . & . & $\mathrm{x}$ & $\mathrm{x}$ & $\mathrm{x}$ & $\mathrm{x}$ & $\mathrm{x}$ \\
\hline Matsushita & 6 & . & $\mathrm{x}$ & $\mathrm{x}$ & $\mathrm{x}$ & $\mathrm{x}$ & $\mathrm{x}$ & $\mathrm{x}$ & . \\
\hline Micron & 5 & . & . & $\mathrm{x}$ & $\mathrm{x}$ & $\mathrm{x}$ & $\mathrm{x}$ & $\mathrm{x}$ & . \\
\hline Mitsubishi & 7 & . & $\mathrm{x}$ & $\mathrm{x}$ & $\mathrm{x}$ & $\mathrm{x}$ & $\mathrm{x}$ & $\mathrm{x}$ & $\mathrm{x}$ \\
\hline Mosel Vitelic & 5 & . & . & $\mathrm{x}$ & $\mathrm{x}$ & $\mathrm{x}$ & $\mathrm{x}$ & $\mathrm{x}$ & . \\
\hline Mostek & 4 & $\mathrm{x}$ & $\mathrm{x}$ & $\mathrm{x}$ & $\mathrm{x}$ & . & . & . & . \\
\hline Motorola & 8 & $\mathrm{x}$ & $\mathrm{x}$ & $\mathrm{x}$ & $\mathrm{x}$ & $\mathrm{x}$ & $\mathrm{x}$ & $\mathrm{x}$ & $\mathrm{x}$ \\
\hline Nan Ya Techn. & 1 & . & . & . & . & . & . & $\mathrm{x}$ & . \\
\hline Ntl. Semic. & 4 & $\mathrm{x}$ & $\mathrm{x}$ & $\mathrm{x}$ & $\mathrm{x}$ & . & . & . & . \\
\hline NEC & 8 & $\mathrm{x}$ & $\mathrm{x}$ & $\mathrm{x}$ & $\mathrm{x}$ & $\mathrm{x}$ & $\mathrm{x}$ & $\mathrm{x}$ & $\mathrm{x}$ \\
\hline Nippon & 4 & . & . & . & $\mathrm{x}$ & $\mathrm{x}$ & $\mathrm{x}$ & $\mathrm{x}$ & . \\
\hline OKI & 5 & . & . & $\mathrm{x}$ & $\mathrm{x}$ & $\mathrm{x}$ & $\mathrm{x}$ & $\mathrm{x}$ & . \\
\hline Ramtron Int. & 1 & . & . & . & . & . & $\mathrm{x}$ & . & . \\
\hline Samsung & 6 & . & . & $\mathrm{x}$ & $\mathrm{x}$ & $\mathrm{x}$ & $\mathrm{x}$ & $\mathrm{x}$ & $\mathrm{x}$ \\
\hline Sanyo & 3 & . & . & . & $\mathrm{x}$ & $\mathrm{x}$ & $\mathrm{x}$ & . & . \\
\hline SGS-Ates & 2 & $\mathrm{x}$ & $\mathrm{x}$ & . & . & . & . & . & . \\
\hline Sharp & 4 & . & . & $\mathrm{x}$ & $\mathrm{x}$ & $\mathrm{x}$ & $\mathrm{x}$ & . & . \\
\hline Siemens & 7 & . & $\mathrm{x}$ & $\mathrm{x}$ & $\mathrm{x}$ & $\mathrm{x}$ & $\mathrm{x}$ & $\mathrm{x}$ & $\mathrm{x}$ \\
\hline Signetics & 2 & $\mathrm{x}$ & $\mathrm{x}$ & . & . & . & . & . & . \\
\hline STC-ITT & 3 & $\mathrm{x}$ & $\mathrm{x}$ & $\mathrm{x}$ & . & . & . & . & . \\
\hline Texas Instr. & 8 & $\mathrm{x}$ & $\mathrm{x}$ & $\mathrm{x}$ & $\mathrm{x}$ & $\mathrm{x}$ & $\mathrm{x}$ & $\mathrm{x}$ & $\mathrm{x}$ \\
\hline Toshiba & 7 & . & $\mathrm{x}$ & $\mathrm{x}$ & $\mathrm{x}$ & $\mathrm{x}$ & $\mathrm{x}$ & $\mathrm{x}$ & $\mathrm{x}$ \\
\hline Vanguard & 2 & . & . & . & . & . & $\mathrm{x}$ & $\mathrm{x}$ & . \\
\hline Zilog & 1 & . & $\mathrm{x}$ & . & . & . & . & . & . \\
\hline
\end{tabular}

Table 1 presents firms being active in markets for specific DRAM generations. The data are taken from Dataquest and encompass the period 1974 to 1996. 
Table 2: Variable definitions and summary statistics

\begin{tabular}{|c|c|c|c|c|}
\hline Variable & Description & Mean & Min. & Max. \\
\hline$P_{64 K, t}$ & $\begin{array}{l}\text { Average selling price of one chip } \\
\text { of generation } 64 K \text { in period } t .\end{array}$ & 20.866 & 0.890 & 241.240 \\
\hline$P_{256 K, t}$ & $\begin{array}{l}\text { Average selling price of one chip } \\
\text { of generation } 256 \mathrm{~K} \text { in period } t .\end{array}$ & 13.828 & 1.265 & 196.130 \\
\hline$P_{1 M b, t}$ & $\begin{array}{l}\text { Average selling price of one chip } \\
\text { of generation } 1 M b \text { in period } t \text {. }\end{array}$ & 16.077 & 2.607 & 130.669 \\
\hline$q_{64 K, t}$ & $\begin{array}{l}\text { Total number of chips of the } 64 K \\
\text { generation being sold in period } t .\end{array}$ & 28.617 & 0 & 264.395 \\
\hline$q_{256 K, t}$ & $\begin{array}{l}\text { Total number of chips of the } 256 K \\
\text { generation being sold in period } t .\end{array}$ & 50.925 & 0 & 242.412 \\
\hline$q_{1 M b, t}$ & $\begin{array}{l}\text { Total number of chips of the } 1 M b \\
\text { generation being sold in period } t \text {. }\end{array}$ & 51.648 & 0 & 215.633 \\
\hline$X_{i, 64 K, t}$ & $\begin{array}{l}\text { Past accumulated output for firm } i \text { offering } \\
\text { generation } 64 K \text { in period } t \text {. }\end{array}$ & 64.115 & 0 & $2,632.794$ \\
\hline$X_{i, 256 K, t}$ & $\begin{array}{l}\text { Past accumulated output for firm } i \text { offering } \\
\text { generation } 256 K \text { in period } t \text {. }\end{array}$ & 82.648 & 0 & $4,681.152$ \\
\hline$X_{i, 1 M b, t}$ & $\begin{array}{l}\text { Past accumulated output for firm } i \text { offering } \\
\text { generation } 256 K \text { in period } t \text {. }\end{array}$ & 47.662 & 0 & $4,694.359$ \\
\hline$q_{i, 64 K, t}$ & $\begin{array}{l}\text { Firm } i \text { 's number of chips from the } \\
64 K \text { generation being sold in period } t \text {. }\end{array}$ & 1.383 & 0 & 264.395 \\
\hline$q_{i, 256 K, t}$ & $\begin{array}{l}\text { Firm } i \text { 's number of chips of the } \\
256 K \text { generation being sold in period } t \text {. }\end{array}$ & 2.612 & 0 & 242.412 \\
\hline$q_{i, 1 M b, t}$ & $\begin{array}{c}\text { Firm } i \text { 's number of chips of the } 1 M b \\
\text { generation being sold in period } t .\end{array}$ & 2.649 & 0 & 215.633 \\
\hline$N O F_{64 K, t}$ & $\begin{array}{l}\text { Number of firms competing in the } \\
\text { market of generation } 64 K \text { at period } t \text {. }\end{array}$ & 10.191 & 0 & 20 \\
\hline$N O F_{256 K, t}$ & $\begin{array}{l}\text { Number of firms competing in the } \\
\text { market of generation } 256 K \text { at period } t \text {. }\end{array}$ & 14.333 & 0 & 19 \\
\hline$N O F_{1 M b, t}$ & $\begin{array}{l}\text { Number of firms competing in the } \\
\text { market of generation } 1 M b \text { at period } t \text {. }\end{array}$ & 15.435 & 0 & 19 \\
\hline$A M S_{64 K, t}$ & $\begin{array}{l}\text { Average market share of firms in } \\
\text { generation } 64 K \text { at period } t .\end{array}$ & 0.165 & 0 & 1 \\
\hline$A M S_{256 K, t}$ & $\begin{array}{l}\text { Average market share of firms in } \\
\text { generation } 256 K \text { at period } t .\end{array}$ & 0.111 & 0 & 1 \\
\hline$A M S_{1 M b, t}$ & $\begin{array}{l}\text { Average market share of firms in } \\
\text { generation } 1 M b \text { at period } t .\end{array}$ & 0.099 & 0 & 1 \\
\hline
\end{tabular}

Table 2 presents summary statistics using quarterly data from 1974 until 1996 provided by Dataquest. All quantities are multiplied by $10^{-6}$ and prices are deflated using the consumer price index. 
Table 3: Inverse demand equations

\begin{tabular}{c|cc|cc|cc}
\hline \hline \multirow{2}{*}{ Variable } & \multicolumn{2}{|c|}{$64 \mathrm{~K}$ generation } & \multicolumn{2}{c|}{$256 \mathrm{~K}$ generation } & \multicolumn{2}{c}{1 1Mb generation } \\
& Estimate & Std. err. & Estimate & Std. err. & Estimate & Std. err. \\
\hline Constant & $638.729^{* *}$ & 43.6654 & $488.089^{* *}$ & 40.747 & $314.070^{* *}$ & 74.414 \\
$q_{16 K}$ & $-2.016^{* *}$ & 0.219 & & & & \\
$q_{64 K}$ & $-0.521^{* *}$ & 0.064 & $-0.543^{* *}$ & 0.066 & & \\
$q_{256 K}$ & $-0.342^{* *}$ & 0.049 & $-0.302^{* *}$ & 0.032 & $-0.270^{* *}$ & 0.054 \\
$q_{1 M b}$ & & & $-0.079^{*}$ & 0.046 & $-0.152^{* *}$ & 0.060 \\
$q_{4 M b}$ & & & & & -0.071 & 0.053 \\
$G D P$ & $-38.601^{* *}$ & 2.802 & $-28.379^{* *}$ & 2.617 & $-16.116^{* *}$ & 5.653 \\
\hline \hline
\end{tabular}

Table 3 presents two-stage least squares estimation results for the inverse demand equations (3), (4), and (5). The dependent variable is industry price (deflated by the consumer price index) for the vintage under consideration. Explanatory variables are the total industry output for the corresponding vintage, industry output for the adjacent vintages and the GDP in electronics (deflated by the consumer price index). All industry quantities and $G D P$ are multiplied by $10^{-6}$. We instrument industry output of generation $k$ using supply shifters, i.e., material, labor and energy prices (factor prices are adjusted using the producer price index), number of firms in the market and a time trend. Heteroscedasticity- and autocorrelation-robust standard errors are shown in the column to right to the parameter estimates, and ${ }^{* *}\left({ }^{*}\right)$ denotes a $99 \%$ ( $\left.90 \%\right)$ level of confidence. The first stage results are available from the author upon request. 
Table 4: Estimation results for the pricing relations

\begin{tabular}{l|cc|cc}
\hline \hline & \multicolumn{2}{|c|}{$\begin{array}{c}\text { Estimates of multi-vintage } \\
\text { firm pricing relation }\end{array}$} & \multicolumn{2}{c}{$\begin{array}{c}\text { Estimates of single-vintage } \\
\text { firm pricing relation }\end{array}$} \\
& \multicolumn{1}{c}{ Estimate } & Std. err. & Estimate & Std. err. \\
\hline $\ln X_{i, 256 K}$ & $-0.341^{* *}$ & 0.123 & $-0.184^{* *}$ & 0.078 \\
$\ln X_{-i, 256 K}$ & $0.047^{* *}$ & 0.009 & $0.045^{* *}$ & 0.008 \\
$\ln X_{i, 64 K}$ & $-0.196^{*}$ & 0.116 & $-0.189^{* *}$ & 0.077 \\
$\ln X_{-i, 64 K}$ & $-0.187^{* *}$ & 0.011 & $-0.131^{* *}$ & 0.008 \\
$\ln q_{i, 256 K}$ & $1.364^{* *}$ & 0.316 & $1.708^{* *}$ & 0.359 \\
$\ln$ mat & $0.101^{* *}$ & 0.025 & $0.113^{* *}$ & 0.027 \\
$\ln$ lab & $0.045^{* *}$ & 0.027 & $0.453^{* *}$ & 0.028 \\
$\ln e$ & $-0.144^{* *}$ & 0.040 & $-0.142^{* *}$ & 0.040 \\
Dyn_Effect & $0.089^{*}$ & 0.056 & $0.129^{* *}$ & 0.051 \\
Firm Dummies & YES** & \multicolumn{3}{|l}{ YES** } \\
\hline \multicolumn{2}{|c|}{ Obs. $=611$, adj. $\mathrm{R}^{2}=0.575$} & Obs.=611, adj. $\mathrm{R}^{2}=0.561$ \\
\hline \hline
\end{tabular}

Table 4 presents the estimation results for the pricing equation (6). Columns (2) and (3) represent the estimation results for the multi-vintage firm specification and columns (4) and (5) represent the single-vintage firm specification. The table shows the estimation results for the $256 \mathrm{~K}$ vintage, which is our benchmark case. The dependent variable is industry price (deflated by the consumer price index). Explanatory variables are the firm-specific past cumulated output for the $64 \mathrm{~K}$ and $256 \mathrm{~K}$ generation, cumulated past output of all other firms for the $64 \mathrm{~K}$ and $256 \mathrm{~K}$ generation, firm-specific contemporaneous output for the $256 \mathrm{~K}$ generation, prices of material, wage and energy (factor prices are adjusted using the producer price index), the mark-up, and firm-specific periods left, and firm-specific dummy variables. We use panel data techniques and instrument contemporaneous firm-specific output for the $256 \mathrm{~K}$ generation, firm-specific past cumulated output for the $256 \mathrm{~K}$ generation and cumulated past output of all other firms for the $256 \mathrm{~K}$ generation using its lagged values. We also use market structure characteristics, such as the number of firms and the average market shares for the $256 \mathrm{~K}$ generation and GDP as a demand shifter. The pricing relations are estimated using two stage least squares. Heteroscedasticity- and autocorrelation-robust standard errors are shown in the column on the right to the parameter estimates. ${ }^{* *}\left({ }^{*}\right)$ denotes a $99 \%(90 \%)$ level of confidence. The first stage results are available from the author upon request. The estimates for learning from others are adjusted by the average number of firms in the market, as we assume that the progrsss of a technology occurs at the industry- or inter-firm level. All learning effects are represented as learning elasticities. 